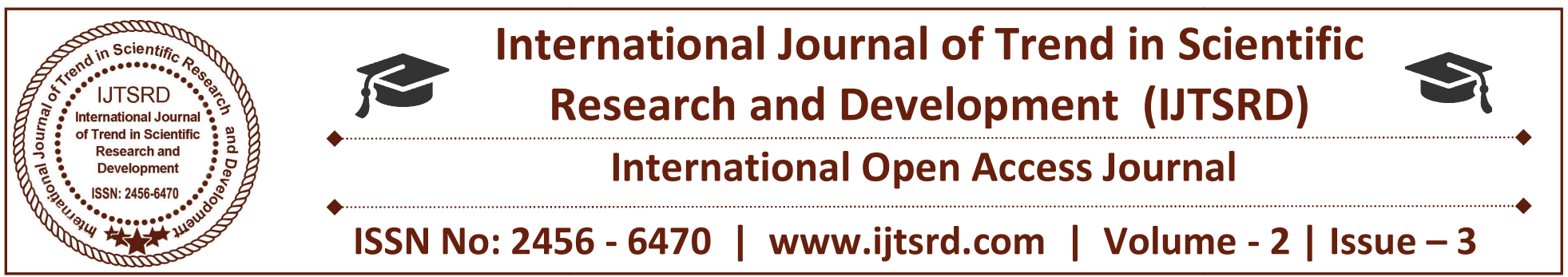

\title{
Health Care Monitor with Emergency Support
}

\author{
K. Ratna, G. Shruthi, R. Sorna Manjari, S. Suryakala, V. Rathinapriya \\ Department of Computer Science and Engineering, \\ Easwari Engineering College, Chennai, Tamil Nadu, India
}

\begin{abstract}
The world of medical science is an emerging area that has accelerated with new technologies and this is the time when the vision of "The internet of things" has turned into reality. People demand more care at reduced clinical costs, remote health monitoring is one of the possible solutions to this demand. Remote health monitoring can be best utilized provided the device is wearable to facilitate continuous self monitoring. In this paper, we propose a system for monitoring of pulse rate, body temperature and oxygen level in blood (vital body parameters) of the person with dedicated sensors along with electrodes using arduino. This system is wearable and also supports remote health monitoring. Remote Health monitoring is attained by storing the collected data to cloud and it can also viewed in an application. In case of any emergency, alert messages are sent to relative's phone numbers. This data can be retrieved by the doctor for analysis anywhere and any aberrancy will be timely detected. Along with remote monitoring and wearability of system, accuracy and cost cannot be ignored.
\end{abstract}

Keywords: Sensors, Electrodes, GSM, Arduino

\section{INTRODUCTION :}

The "Internet of things" - IOT is a concept and model consisting of sensors, actuators and development boards interacting with each other connected over the internet without any human intervention resulting into a more intelligent system. In simple words, IOT refers to a network of objects all connected to the internet at the same time. The main principle of Internet of things (IOT) is that the objects/things i.e. sensor nodes identify, sense, process and communicate with each other. IoT has a substantial influence in healthcare domain.

Still, there are so many people who do not have access to quality healthcare services, thus remote patient monitoring becomes a need. Presently Healthcare system is shattered with the lack of communication between the patients and the doctors. Thus $\bigcirc$ to $/$ address this problem information technologybecomes a need. Healthcare services can be improved a lotwith IoT-enabled healthcare devices. By applying IoT concepts in healthcare, there is a great possibility of virtually saving the lives. E-health solutions based on IoT should provide worth information about health to the patients and the doctors can make better decisions irrespective of their patient's location. IoT has already brought changes in various domains of health care like intelligent healthcare tools and devices, diagnostics and monitoring of patients, data storage, transfer, and collaborations. Thus, a system consisting of wearable temperature, pulse rate sensor, electrodes along with arduino is designed. Once the data is received by the arduino board it will be sent to the cloud, the data stored in the cloud can be retrieved by the doctor and it can also be viewed in an application. Alert messages are sent to relative's phone numbers in case of any emergency. The proposed system will be really helpful in reducing a person's unnecessary visits to a doctor since the person's health monitoring is done on a real-time basis. Apart from this the diseases can be timely detected and treated; errors will be reduced as the data is stored at cloud automatically without human intervention. 


\section{Literature survey:}

\section{1: Resting heart rate estimation using PIR sensors}

Pyroelectric infrared sensor (PIR) and Photoplethysmogram sensor (PPG) has a major role in estimating the resting heart rate and validation of the ambient sensor at a low cost. The derivative of the discrete - time PIR sensor is used in extracting heart beat signal. The major issue here is - the experimental results shows only $95 \%$ of the estimated heart rate values are within 4 beats per minute. Average measurements observed using the PPG sensor is 75.5 beats per minute and using the PIR sensor is 74.7 beats per minute.

\section{2: Flexible heartbeat sensor for wearable device}

A flexible strain - gauge sensor is majorly used and it is fabricated using a double - sided fabrication method with polymer and metal (polyimide and nickel - chrome). This sensor is compatible with flexible printed circuit board. It helps to detect a bending radius from $5 \mathrm{~mm}$ to $100 \mathrm{~mm}$. When compared with the sensitivity of optical Photoplethysmography sensors (PPG) the flexible heart beat sensor is highly sensitive. By using this proposed sensor we can develop wearable smart devices which require heart beat detection and various other applications.

\section{3: Spot and continuous monitoring of heart rate} by combining time and frequency domain analysis of photoplethysmographic signals at rest conditions

The main target of this system is to develop a wearable device to calculate the Heart Rate at rest conditions. Calculating the heart rate with the help of thePhotoplethysmography sensors (PPG) gives 100\% accuracy at the rest positions. This system gives result close to standard Electro Cardio Gram (ECG) device results. This accuracy fails when body movements are encountered in the system and this is one of the major issues.

\section{4: Evaluating the accuracy of wearable heart rate monitors}

Photoplethysmography sensors (PPG) are popularly used to determine the heart rate even though its accuracy is not $100 \%$ when compared with Electro Cardio Gram (ECG). This technology is used in wearable devices to monitor heart rate. When the results of Photoplethysmography sensors (PPG) and Electro Cardio Gram (ECG) are compared, they remain the same at rest conditions while a maximum of $10 \%$ variation is observed during body movements.

2.5: Evaluation of the accuracy and reliability for photoplethysmography based heart rate and beatto-beat detection during daily activities

The study shows the results of using two wrist - worn devices namely PulseOn (PO) and Empatica (E4), by measuring the PPG based heart rate and inter heartbeat intervals. The accuracy and reliability are evaluated with respect to Electro Cardio Gram sensors (ECG) during different daily activities. There is a decrease in accuracy and reliability of the devices due to excessive hand movements. While at rest the percentage of correctly detected heart beat is $89 \%$ for PulseOn (PO) and 68\% for Empatica (E4). During hand movements it is $76 \%$ for PulseOn (PO) and only 9\% for Empatica (E4). PulseOn (PO) shows better inter heartbeat detection accuracy than Empatica (E4) in all activities.

\section{6: Patient Monitoring System Based on Internet of Things}

The main purpose of this paper work is to develop a solution based on ontology with ability to monitor the health status and recommendations of workouts with chronic diseases architecture. It uses glucometer and ECG signals to find glucose level in blood and pulse rate.

\section{7: Health Care Monitoring System in Internet of Things (loT) by Using RFID}

RFID, NFC and small sensor nodes are used to here to find a person's pulse rate, bloodpressure, temperature, blood glucose level. Here all the sensors are connected to arduino and then to the Wifi module. So without internet connection, it is difficult to get the data.

\section{8: Remote prescription and I-Home healthcare based on IoT}

When the finger is placed on its sensor it measure the heart beat per second. Through the raspberry pi, the sensor readings are received and it can be displayed by monitor. If the patient's abnormal heart condition has not recovered within a certain time period, e.g., 10 min, the iMedBox will automatically send out a text message to the doctor.It will helps to doctors and 
family members to Checking whether they are following their prescribed treatment on time by Real Time Clock (RTC) and RFID tags.

\section{9: Remote health monitoring system for detecting cardiac disorders}

The sensor transmits ECG data to the user's smartphone using Bluetooth. It is deployed as an Android Service. It supports seamless capture of 12lead ECG data from HW6E via Bluetooth and transfers the data over HyperText Transfer Protocol (HTTP) using proprietary JavaScript Object Notation messages with $3 \mathrm{G} /$ wireless fidelity (Wi-Fi). It is capable of receiving notifications sent by the server and also has a provision for sending symptoms and demographic information.

\subsection{0: Incorporating Health Monitoring and Duress} Detection into Mobile Device Authentication

The work describes the use of Electroencephalogram (EEG) for authentication. When mature, this technology may be trusted to uniquely authenticate an individual using a single factor. It addresses the needs and constraints faced by first responders in the near term. It is an active approach that continuously monitors the user and fails authentication only when the user readiness status is deemed to be weak.

Tabular column:

\begin{tabular}{|c|c|c|c|c|}
\hline S.No & Paper & pproach & Result & Issues \\
\hline 1. & IR sensors rate estimation & $\begin{array}{l}\text { Pyroelectric } \\
\text { infrared sensor (PIR) and } \\
\text { Photoplethysmogram } \\
\text { sensor (PPG) are majorly } \\
\text { used. }\end{array}$ & $\begin{array}{l}95 \% \text { of the } \\
\text { estimated heart } \\
\text { rate values are } \\
\text { within } 4 \text { beats per } \\
\text { minute. }\end{array}$ & \begin{tabular}{lr}
\multicolumn{2}{l}{ Heart rate } \\
calculated be \\
during & only \\
conditions. & rest \\
\end{tabular} \\
\hline 2. & $\begin{array}{l}\text { Flexible heartbeat sensor for } \\
\text { wearable device }\end{array}$ & $\begin{array}{l}\text { Flexible strain gauge } \\
\text { sensor is compatible with } \\
\text { flexible printed h circuit } \\
\text { board. }\end{array}$ & $\begin{array}{l}\text { This sensor } \\
\text { detects a bending } \\
\text { radius from } 5 \mathrm{~mm} \\
\text { to } 100 \mathrm{~mm} \text {. }\end{array}$ & $\begin{array}{l}\text { racy is } \\
\text { d. }\end{array}$ \\
\hline 3. & $\begin{array}{l}\text { Spot and continuous } \\
\text { monitoring of heart rate by } \\
\text { combining time and frequency } \\
\text { domain analysis } \\
\text { photoplethysmographic } \\
\text { signals at rest conditions }\end{array}$ & $\begin{array}{l}\text { Photoplethysmogram } \\
\text { sensor (PPG) are majorly } \\
\text { used. SN: } 2456=6470 \\
\end{array}$ & $\begin{array}{l}100 \% \text { accur: } \\
\text { rest conditio }\end{array}$ & $\begin{array}{l}\text { This accuracy } \\
\text { fails when body } \\
\text { movements are } \\
\text { encountered. }\end{array}$ \\
\hline 4. & $\begin{array}{l}\text { luating the accuracy of } \\
\text { rrable heart rate monitors }\end{array}$ & $\begin{array}{l}\text { Photoplethysmography } \\
\text { sensors (PPG) are } \\
\text { popularly used though its } \\
\text { accuracy is not } 100 \% \text {. }\end{array}$ & $\begin{array}{lr}\text { Gives the same } \\
\text { results when } \\
\text { compared with } \\
\begin{array}{ll}\text { ECG at rest } \\
\text { conditions. }\end{array} \\
\end{array}$ & $\begin{array}{l}\text { A maximum of } \\
10 \% \text { variation is } \\
\text { observed during } \\
\text { body movements. }\end{array}$ \\
\hline 5. & $\begin{array}{l}\text { Evaluation of the accuracy } \\
\text { and reliability for } \\
\text { photoplethysmography based } \\
\text { heart rate and beat-to-beat } \\
\text { detection during daily } \\
\text { activities }\end{array}$ & $\begin{array}{l}\text { PulseOn (PO) and } \\
\text { Empatica E4 (E4) are the } \\
\text { two wearable devices } \\
\text { being used. }\end{array}$ & $\begin{array}{lr}\text { PulseOn } & (\mathrm{PO}) \\
\text { shows better } & \text { inter } \\
\text { heart } & \text { beat } \\
\text { detection } & \\
\text { accuracy } & \text { than } \\
\text { Empatica E4. }\end{array}$ & $\begin{array}{l}\text { Empatica } \quad \text { E4 } \\
\text { gives only } 68 \% \\
\text { accuracy during } \\
\text { rest and only } 9 \% \\
\text { accuracy during } \\
\text { hand movements. }\end{array}$ \\
\hline 6. & $\begin{array}{l}\text { Patient Monitoring System } \\
\text { Based on Internet of Things }\end{array}$ & $\begin{array}{l}\text { Internet is used as a } \\
\text { medium } \\
\text { communication. }\end{array}$ & \begin{tabular}{|l} 
Constant \\
monitoring by the \\
doctor to the \\
patients with \\
chronic diseases \\
and r timely
\end{tabular} & $\begin{array}{l}\text { There might be } \\
\text { loss of internet } \\
\text { connection during } \\
\text { emergency. }\end{array}$ \\
\hline
\end{tabular}


International Journal of Trend in Scientific Research and Development (IJTSRD) ISSN: 2456-6470

\begin{tabular}{|c|c|c|c|c|}
\hline & & & $\begin{array}{l}\text { treatment being } \\
\text { provided. }\end{array}$ & \\
\hline 7. & $\begin{array}{l}\text { Health Care Monitoring } \\
\text { System in Internet of Things } \\
\text { (loT) by Using RFID }\end{array}$ & $\begin{array}{l}\text { RFID and Zigbee play the } \\
\text { main role }\end{array}$ & $\begin{array}{l}\text { The data from the } \\
\text { sensors are } \\
\text { uploaded to the } \\
\text { cloud and mail is } \\
\text { sent for alerting. }\end{array}$ & $\begin{array}{l}\text { Without internet } \\
\text { connection, } \\
\text { cannot send alert } \\
\text { messages. }\end{array}$ \\
\hline 8. & $\begin{array}{l}\text { Remote prescription and I- } \\
\text { Home healthcare based on IoT }\end{array}$ & $\begin{array}{l}\text { RTC and RFID is used } \\
\text { here }\end{array}$ & $\begin{array}{l}\text { Heart beat rates } \\
\text { are measured and } \\
\text { sms is sent to } \\
\text { doctor and family } \\
\text { members }\end{array}$ & \begin{tabular}{l}
\multicolumn{3}{l}{ Internet } \\
connection is \\
always required \\
and does not \\
show \\
accuracy
\end{tabular} \\
\hline 9. & $\begin{array}{l}\text { Remote health monitoring } \\
\text { system for detecting cardiac } \\
\text { disorders }\end{array}$ & $\begin{array}{l}\text { LED ECG sensors, } \\
\text { Bluetooth and HTTP } \\
\text { protocol }\end{array}$ & $\begin{array}{l}\text { Early detection of } \\
\text { acute episodes of } \\
\text { MI }\end{array}$ & $\begin{array}{l}\text { Does not give } \\
\text { potential } \\
\text { information about } \\
\text { ECG signals }\end{array}$ \\
\hline 10. & $\begin{array}{ll}\text { Incorporating } & \text { Health } \\
\text { Monitoring and } & \text { Duress } \\
\begin{array}{l}\text { Detection into Mobile Device } \\
\text { Authentication }\end{array} & \end{array}$ & $\begin{array}{l}\text { Kalman filters compute } \\
\text { predicted values for } \\
\text { variables }\end{array}$ & $\begin{array}{l}\text { Continuously } \\
\text { monitors and fails } \\
\text { authentication } \\
\text { when the user is } \\
\text { weak }\end{array}$ & $\begin{array}{lr}\text { User will lose } \\
\text { connectivity } \\
\text { remote areas }\end{array}$ \\
\hline
\end{tabular}

\section{Conclusion:}

From the review of different papers, it is concluded that there are various methods to collect and store data about the vital body parameters. But each paper contains issues and problems. Since PPG signals are not accurate during body movements, ECG should be used to find the pulse rate accurately. Alert messages are sent to both patients and relatives in case of emergency.

\section{Future works:}

When going to product level, this system can be compact and fit for everyday use.

\section{REFERENCE:}

1. Hemanth Kapu ${ }^{\mathrm{a}}$, Kavisha Saraswat ${ }^{\mathrm{a}}$, Yusuf Ozturk", A. Enis Cetin" estimation using PIR sensors", Infrared Physics \&Technology, International Research Journal, Volume 85,September 2017.

2. Yeon Hwa Kwak ${ }^{\mathrm{ab}}$, Wonhyo Kim ${ }^{\mathrm{a}}$, Kwang Bum Park $^{\mathrm{a}}$, Kunnyun Kim ${ }^{\mathrm{a}}$, Sungkyu Seo ${ }^{\mathrm{b}}$, "Flexible heartbeat sensor for wearable device",
Biosensors and Bioelectronics, International Research Journal, Volume 94, August 2016.

3. Madhan Mohan P.; Nagarajan V.; Vignesh J. C., "Spot and continuousmonitoring of heartratebycombiningtime and

frequencydomainanalysis photoplethysmographic signals at rest conditions" , IET Signal Processing, IEEE Journal, Volume 11, December 2017.

4. [4] Z. Ge; P. W. C. Prasad; N. Costadopoulos; Abeer Alsadoon; A. K. Singh; A. Elchouemi, "Evaluating the accuracy of wearableheartratemonitors", 2nd International Conference on Advances in Computing, Communication, \& Automation (ICACCA) (Fall), November 2016.

5. Julia Pietila, Saeed Mehrang, Johanna Tolonen, Elina Helander, Holly Jimison, Misha Pavel, Ilkka Korhonen, "Evaluation of the accuracy and reliability for photoplethysmography based heart rate and beat-to-beat detection during daily activities",European Medical and 
Biological Engineering Conference, IFMBE, Volume 65, June 2017.

6. Jorge Gómeza, Byron Oviedob, Emilio Zhumab, "Patient Monitoring System Based on Internet of Things",7th International Conference on Ambient Systems, Networks and Technologies, Volume 83, May 2016.

7. Sarfraz Fayaz Khan, "Health Care Monitoring System in Internet of Things (loT) by Using RFID", 6th International Conference on Industrial Technology and Management, May 2017.

8. S.Lavanya, G.Lavanya, J.Divyabarathi, "Remote prescription and I-Home healthcare based on IoT", IEEE International Conference on Innovations in Green Energy and Healthcare Technologies(ICIGEHT'17), November 2017.

9. Ayush Bansal, Sunil Kumar, Anurag Bajpai, Vijay N. Tiwari, Mithun Nayak, Shankar Venkatesan, Rangavittal Narayanan, "Remote health monitoring system for detecting cardiac disorders", IET System Biology, Volume 9, November 2015.

10. Susan Gottschlich, "Incorporating Health Monitoring and Duress Detection into Mobile Device Authentication", IEEE International Symposium on Technologies for Homeland Security (HST), April 2017. 